\title{
miR-17-5p drives G2/M-phase accumulation by directly targeting CCNG2 and is related to recurrence of head and neck squamous cell carcinoma
}

\author{
Qiang Huang ${ }^{1 \dagger}$, Yu-Jie Shen ${ }^{1 \dagger}$, Chi-Yao Hsueh ${ }^{1 \dagger}$, Yang Guo ${ }^{1}$, Yi-Fan Zhang ${ }^{1}$, Jiao-Yu Li ${ }^{2}$ and Liang Zhou ${ }^{1 *}$
}

\begin{abstract}
Background: The human miR-17-92 polycistron is the first reported and most well-studied onco-miRNA with a cluster of seven miRNAs. miR-17-5p, a member of the miR-17-92 family, plays an important role in tumor cell proliferation, apoptosis, migration and invasion. However, few studies have shown the role of miR-17-5p in the cell cycle of head and neck squamous cell carcinoma (HNSCC).

Methods: RT-qPCR was used to detect miR-17-5p expression levels in 64 HNSCC tissues and 5 cell lines. The relationship between the expression of miR-17-5p in the tissues and the clinical characteristics of the patients was analyzed. HNSCC cells were transfected with an miR-17-5p mimic or inhibitor to evaluate cell cycle distribution by flow cytometry. Cell cycle distribution of cells transfected with target gene was evaluated using flow cytometry. Dual-luciferase reporter assay was used to detect the regulatory effect of miR-17-5p on target gene expression.

Results: In the present study, we found that miR-17-5p expression in HNSCC tissues and cell lines was remarkably increased, and miR-17-5p is related to recurrence in HNSCC patients. Silencing miR-17-5p blocked HNSCC cells in G2/M phase, whereas its overexpression propelled cell cycle progression. More importantly, we verified that miR-17$5 p$ negatively regulated CCNG2 mRNA and protein expression by directly targeting its $3^{\prime} U T R$.
\end{abstract}

Conclusion: These findings suggest that miR-17-5p might act as a tumor promoter and prognostic factor for recurrence in HNSCC patients.

Keywords: miR-17-5p, HNSCC, Cell cycle, CCNG2, Recurrence

\section{Introduction}

Head and neck squamous cell carcinoma (HNSCC) was the seventh most common cancer worldwide in 2018 (890,000 new cases and 450,000 deaths), accounting for $3 \%$ of all cancers and just over $1.5 \%$ of all cancer deaths in the United States [1]. Despite advances in diagnosis

\footnotetext{
* Correspondence: zhoulent@126.com

${ }^{\dagger}$ Qiang Huang, Yu-Jie Shen and Chi-Yao Hsueh contributed equally to this work.

'Department of Otorhinolaryngology, Eye \& ENT Hospital, Fudan University, Shanghai 200031, China

Full list of author information is available at the end of the article
}

and treatment, recurrent, or metastatic disease (or both) develops in more than $65 \%$ of patients with head and neck cancer [2]. Therefore, a better understanding of the molecular mechanisms of HNSCC is an urgent matter.

The cell cycle is a highly organized and systematically controlled process. Dysregulation of cell cycle control, such as unscheduled proliferation, is regarded as one of the key drivers of genomic and chromosomal instability that facilitates tumorigenesis [3, 4]. MicroRNAs (miRNAs) are vital post-transcriptional modulators that directly target mRNA at the 3 -untranslated region (UTR)

(c) The Author(s). 2021 Open Access This article is licensed under a Creative Commons Attribution 4.0 International License, which permits use, sharing, adaptation, distribution and reproduction in any medium or format, as long as you give appropriate credit to the original author(s) and the source, provide a link to the Creative Commons licence, and indicate if changes were made. The images or other third party material in this article are included in the article's Creative Commons licence, unless indicated otherwise in a credit line to the material. If material is not included in the article's Creative Commons licence and your intended use is not permitted by statutory regulation or exceeds the permitted use, you will need to obtain permission directly from the copyright holder. To view a copy of this licence, visit http://creativecommons.org/licenses/by/4.0/ The Creative Commons Public Domain Dedication waiver (http://creativecommons.org/publicdomain/zero/1.0/) applies to the data made available in this article, unless otherwise stated in a credit line to the data. 
for transcriptional repression or degradation [5]. miRNAs are involved in the progression of the cell cycle of cancer cells $[6,7]$. The human miR-17-92 polycistron is the first reported and most well-studied onco-miRNA with a cluster of seven miRNAs, including miR-17-5p, derived from the c-myc-regulated C13orf25 locus at chromosome 13q31.3 [8]. miR-17-5p has been implicated in cancer development, including proliferation, apoptosis, migration, and invasion. Wang et al. found that dysregulation of miR-17-5p/PIK3R1 axis participated in laryngeal squamous cell carcinoma (LSCC) cell proliferation and apoptosis by inhibiting the activation of the PI3K/AKT signaling pathway [5]. Zhu et al. demonstrated that miR-17-5p enhanced cancer cell proliferation by altering cell cycle profiles via the disruption of RBL2/E2F4-repressing complexes in pancreatic cancer [9]. In our previous study, we presented comprehensive profiling of miRNAs in HNSCC. Several miRNAs were validated, including upregulation of miR-17, miR-21, miR-93, miR-205 and miR-708 and downregulation of miR-125b and miR-145 [10]. However, few studies have shown the role of miR-17-5p in the cell cycle of HNSCC.

The cell cycle is controlled by cyclin-dependent protein kinase (CDK), and its activity is regulated by cyclin and CDK inhibitors [11]. The eight cyclins reported in mammals, cyclins A to $\mathrm{H}$, share a conservative amino acid sequence of about 90 residues, called the cyclin box. The amino acid sequence of cyclin $G$ is very conserved in mammals. The nucleotide sequences of cyclin G1 and cyclin G2 are 53\% identical [12]. Unlike cyclin G1, cyclin G2 (CCNG2) contains a C-terminal protein epitope signature tag (PEST) protein destabilizing motif, indicating that cyclin G2 expression is strictly regulated during the cell cycle. Although CCNG2 has been found to be connected with cancer stemness and chemoresistance of HNSCC cells [13], the role of CCNG2 during cell cycle process of HNSCC has not been completely understood.

This study aims to clarify the role of miR-17-5p in the cell cycle process of HNSCC and the correlation with clinical characteristics of patients with HNSCC, and to study the target genes that miR-17-5p may regulate by bioinformatics methods and dual-luciferase reporter assay exploring the mechanism of miR-17-5p related cell cycle changes in HNSCC.

\section{Methods and material}

\section{Patient information and ethics approval}

Formalin-fixed and paraffin-embedded HNSCC tissues (mainly laryngeal cancer and hypopharyngeal cancer) were obtained from 64 patients diagnosed with HNSCC pathologically after surgery from April 2010 to August 2010 from the Department of Otorhinolaryngology, Eye \& ENT Hospital of Fudan University. The inclusion criteria were as follows: (a) presence of a signed informed consent form obtained before the operation and (b) confirmation of HNSCC by experienced pathologists and classification of tumor stage according to the 8th edition of the AJCC cancer staging manual with complete clinical, imaging, laboratory, and pathological data. The exclusion criteria were as follows: (a) histopathological confirmation of multiple types of primary HNSCC, (b) preoperative treatment with approaches such as radiotherapy or chemotherapy, or (c) infectious disease or autoimmune disease.

In parallel, tissues obtained from 18 patients diagnosed with vocal cord polyps were used as non-tumor control. Relevant clinicopathological and prognostic information was collected. All participants provided written informed consent. The protocols were authorized by the Clinical Research Ethics Committee of the Eye \& ENT Hospital of Fudan University (NO.KJ2008-01).

\section{Cell culture}

The HNSCC cell line AMC-HN8, which was established by Kim et al. [14] in 1997 from patients with head and neck cancer, was maintained in our laboratory. Tu686 was obtained from Central South University (Hunan, China). FaDu and Detroit562 were obtained from the Cell Bank of the Shanghai Institute of Cells, Chinese Academy of Science (Shanghai, China). HNSCC cell lines were cultured in DMEM (Gibco, Grand Island, $\mathrm{NY}$ ), except for AMC-HN8, which was cultured in RPMI-1640 (HyClone, Logan, UT). Growth medium contained 1\% penicillin-streptomycin (Genom Biotechnology, China) and 10\% fetal bovine serum (FBS; Gibco, Grand Island, NY). Cells were incubated with 5\% CO2 at $37^{\circ} \mathrm{C}$. HuLa-PC, a cell line derived from posterior commissure of the larynx, was obtained from ATCC (Gaithersburg, Maryland) and cultured in Dermal Cell Basal Medium (ATCC ${ }^{\circ}$ PCS-200-030 ${ }^{\mathrm{mm}}$ ) supplied with Keratinocyte Growth Kit (ATCC ${ }^{\oplus}$ PCS-200-040 $0^{\text {max }}$ [15].

\section{RT-qPCR}

Total RNA was isolated from tissues with an RNeasy FFPE Kit (QIAGEN, Germany) and cell lines with TRIzol reagent (Invitrogen, Thermo Fisher Scientific) and then reversed-transcribed using an miScript II RT Kit (QIAG EN). qRT-PCR was conducted using the miScript SYBR Green PCR Kit for miRNA using U6 as an internal control and QuantiNova $\mathrm{SYBR}^{\circ}$ Green PCR Kit for mRNA (both from QIAGEN) with the ABI 7500 Real-Time PCR System (Life Technologies, Shanghai, China). The primers were synthesized by Sangon Biotech (Shanghai). The sequences of all primers used are listed in Table 1.

\section{Plasmid, siRNA and miRNA transfection}

Hsa-miR-17-5p mimic, 5' -CAAAGUGCUUACAGUGCA GGUAG-3' (sense) and 5' -ACCUGCACUGUAAGCACU 
Table 1 Sequences of primers

\begin{tabular}{|c|c|c|}
\hline Primer & Forward & Reverse \\
\hline miR-17-5p & CCAAAGTGCTTACAGTGCAGGTA & $\mathrm{N} / \mathrm{A}$ \\
\hline Cyclin A2 & GGATGGTAGTTITGAGTCACCAC & CACGAGGATAGCTCTCATACTGT \\
\hline Cyclin B1 & AATAAGGCGAAGATCAACATGGC & TITGTTACCAATGTCCCCAAGAG \\
\hline Cyclin D1 & GCTGCGAAGTGGAAACCATC & СCTCCTTCTGCACACATTTGAA \\
\hline Cyclin E2 & TCAAGACGAAGTAGCCGTTTAC & TGACATCCTGGGTAGTIITCCTC \\
\hline Cyclin G2 & TCTCGGGTTGTTGAACGTCTA & GTAGCCTCAATCAAACTCAGCC \\
\hline CDK1 & AAACTACAGGTCAAGTGGTAGCC & TCCTGCATAAGCACATCCTGA \\
\hline CDK2 & GTACCTCCCCTGGATGAAGAT & CGAAATCCGCTTGTTAGGGTC \\
\hline CDK4 & TCAGCACAGTTCGTGAGGTG & GTCCATCAGCCGGACAACAT \\
\hline CDK6 & TCTTCATTCACACCGAGTAGTGC & TGAGGTTAGAGCCATCTGGAAA \\
\hline GAPDH & TGTAGTTGAGGTCAATGAAGGG & ACATCGCTCAGACACCATG \\
\hline
\end{tabular}

UUGUU-3' (antisense), and inhibitor, 5'-CUACCU GCACUGUAAGCACUUUG-3' (sense), were designed and synthesized by Sangon Biotech (Shanghai). The CCNG2 overexpression plasmid (NM_004354.3) and empty plasmid were obtained from Genomeditech (Shanghai, China). The transfection was performed with Lipofectamine 2000 (Invitrogen, Carlsbad, CA) according to the manufacturer's instructions.

\section{Cell cycle assay}

The effects of miR-17-5p and CCNG2 on the progress of the cell cycle were investigated using the propidium iodide technique. Briefly, after transfecting with miRNA, siRNA, or plasmid for $24 \mathrm{~h}$, the HNSCC cells were starved for further $24 \mathrm{~h}$ in serum-free culture medium to synchronize. Cells were then fixed in $75 \%$ pre-cooling ethanol overnight at $-20{ }^{\circ} \mathrm{C}$, washed twice with PBS, and then incubated with $500 \mu \mathrm{L} \mathrm{PI} / \mathrm{RNase}$ staining buffer (BD Biosciences) for $15 \mathrm{~min}$ in dark. Cells were then tested using flow cytometry (SP8 MoFlo XDP, Beckman Coulter), and the cell cycle distribution was investigated with FlowJo Software (FlowJo LLC).

\section{Western blotting}

Protein concentrations were detected with BCA (Beyotime, China). Rabbit anti-CCNG2 antibody (Sigma-Aldrich, Cat. \#HPA034684, 1:1000) in 5\% BSA were used. Refer to our previous articles for the rest of the steps $[16,17]$.

\section{Dual-luciferase reporter assay}

The binding sites between miR-17-5p and CCNG2 were predicted by Targetscan. $293 \mathrm{~T}$ cells were cotransfected with CCNG2-wild-type (WT) 3' untranslated region (UTR) luciferase reporter/CCNG2-mutant-type (MU) 3'UTR luciferase reporter and miR-17-5p mimic/mimic NC. Luciferase activities were measured $48 \mathrm{~h}$ after transfection.

\section{Database information}

The ENCORI Pan-Cancer Analysis Platform (http:// starbase.sysu.edu.cn/index.php) was used to perform a differential expression analysis of genes.

\section{Statistical analysis}

Statistical analysis was performed using Student's t-test or one-way analysis of variance (ANOVA), except if specified otherwise in the figure legend. Results are expressed as the means \pm standard deviation (SD). A $p$ value was considered significant as the following: ${ }^{*} p<0.05 ; * p<$ $0.01 ;{ }^{* * * *} p<0.001$. Results that were not statistically significant are labeled as ns. Data were plotted and analyzed using GraphPad Prism 8.

\section{Results}

miR-17-5p is upregulated in HNSCC tissues and cell lines and is related to HNSCC recurrence

To investigate the role of miR-17-5p in HNSCC development, we first ascertained the level of miR-17-5p in HNSCC tissues. qRT-PCR result showed that miR-17-5p level was significantly upregulated in HNSCC tissues $(n=64)$ compared with that in vocal cord polys tissues $(n=18)$ (Fig. 1A). Univariate analysis revealed that miR17-5p levels in HNSCC tissues of patients with recurrence $(n=23)$ were significantly higher than those of patients without recurrence $(n=41 ; p=0.019$; Table 2$)$. Multivariate analysis showed that lymph node metastasis $(p=0.003)$ and miR-17-5p $(p=0.027)$ were independent risk factors for HNSCC (Fig. 1B).

Importantly, we found that HNSCC patients with higher levels of miR-17-5p had a higher likelihood of recurrence compared with patients who had a lower level of miR-17-5p ( $p=0.0023$; Fig. $1 \mathrm{C})$. The AUC for miR17-5p distinguishing HNSCC patients with recurrence from patients without recurrence was 0.7253 (95\% CI: 0.5991 to $0.8516 ; p<0.0029$; Fig. $1 \mathrm{D})$, suggesting that 


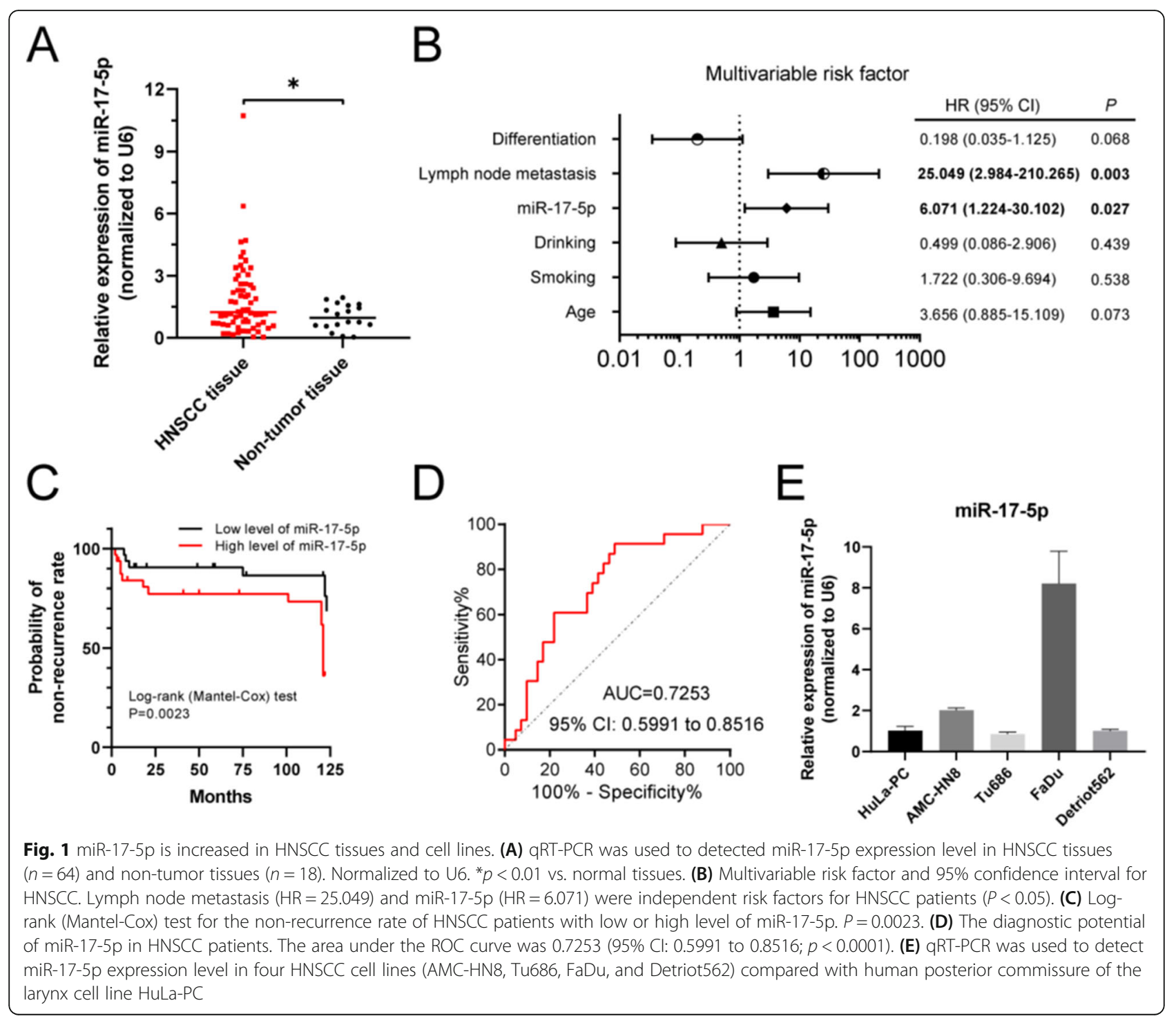

miR-17-5p is related to recurrence in HNSCC patients (sensitivity: $60.87 \%$, specificity: $78.05 \%$ ).

Moreover, we examined the miR-17-5p expression levels in disparate HNSCC cell lines (AMC-HN8, Tu686, $\mathrm{FaDu}$, and Detriot562) compared with that in the human posterior commissure of the larynx cell line HuLa-PC. Levels of miR-17-5p were higher in AMC-HN8 and $\mathrm{FaDu}$ than in HuLa-PC but did not increase in Tu686 and Detriot562 (Fig. 1E). These results suggest that the miR-17-5p is upregulated in HNSCC and may be correlated with HNSCC recurrence.

miR-17-5p promotes cell cycle progress in HNSCC in vitro Previous studies have confirmed that miR-17-5p plays a role in promoting cell cycle progression as an oncomiRNA associated with a variety of cancers $[9,18]$. Consequently, we aimed to investigate whether miR-17-5p is involved in HNSCC cell cycle. Cell cycle phase distribution was detected by flow cytometry. The inhibition of miR-17-5p resulted in an increase in cells at the $S$ phase (from 2.74 to $8.76 \%$ ) and a decrease in cells at G2/M phase (from 40.1 to $29.8 \%$ ) in FaDu cells, not in AMCHN8. By contrast, the overexpression of miR-17-5p in Tu686 cells, not in Detriot562, led to a decrease in cells at the S phase (from 25.9 to $16.8 \%$ ) and an increase in cells at G2/M phase (from 15 to $21.2 \%$, Fig. $2 \mathrm{~A}$ ). We also detected the expression levels of cell cycle-related genes in the two HNSCC cells. We found that CCNA2, CCNB1 and CDK1/2, which regulate cell cycle progress, were decreased in miR-17-5p inhibitor-transfected $\mathrm{FaDu}$ cells but increased in miR-17-5p mimic-transfected Tu686 cells (Fig. 2B). Therefore, these results suggest that miR-17-5p might play a role in promoting cell cycle progress in HNSCC in vitro. 
Table 2 Clinicopathologic characteristics of HNSCC patients

\begin{tabular}{|c|c|c|c|c|}
\hline \multirow[t]{2}{*}{ Features } & \multirow[t]{2}{*}{ All cases } & \multicolumn{2}{|l|}{ miR-17-5p } & \multirow[t]{2}{*}{$p$ value } \\
\hline & & Low $(n=32)$ & High $(n=32)$ & \\
\hline \multirow[t]{3}{*}{ Age (years) } & & & & 0.617 \\
\hline & $\leq 60$ & 17 & 15 & \\
\hline & $>60$ & 15 & 17 & \\
\hline \multirow[t]{3}{*}{ Gender } & & & & 0.551 \\
\hline & Male & 31 & 30 & \\
\hline & Female & 1 & 2 & \\
\hline \multirow[t]{3}{*}{ Smoking } & & & & 0.309 \\
\hline & No & 15 & 11 & \\
\hline & Yes & 17 & 21 & \\
\hline \multirow[t]{3}{*}{ Drinking } & & & & 0.448 \\
\hline & No & 17 & 20 & \\
\hline & Yes & 15 & 12 & \\
\hline \multirow[t]{3}{*}{ Hypertension } & & & & 0.442 \\
\hline & No & 21 & 18 & \\
\hline & Yes & 11 & 14 & \\
\hline \multirow[t]{3}{*}{ Diabetes } & & & & 0.719 \\
\hline & No & 28 & 27 & \\
\hline & Yes & 4 & 5 & \\
\hline \multirow[t]{3}{*}{ Lymph node metastasis } & & & & 0.768 \\
\hline & Negative & 25 & 24 & \\
\hline & Positive & 7 & 8 & \\
\hline \multirow[t]{3}{*}{ TNM stage } & & & & 0.076 \\
\hline & $I+\|$ & 17 & 10 & \\
\hline & $I I I+I V$ & 15 & 22 & \\
\hline \multirow[t]{3}{*}{ Differentiation } & & & & 0.062 \\
\hline & Well+ well-moderately & 14 & 7 & \\
\hline & Moderately+ Moderately-poorly & 18 & 25 & \\
\hline \multirow[t]{3}{*}{ Recurrence } & & & & 0.019 \\
\hline & No & 25 & 16 & \\
\hline & Yes & 7 & 16 & \\
\hline \multirow[t]{3}{*}{ Death } & & & & 0.095 \\
\hline & No & 26 & 20 & \\
\hline & Yes & 6 & 12 & \\
\hline
\end{tabular}

\section{CCNG2 is a direct target gene of miR-17-5p}

In order to study the mechanism by which miR-17-5p drives HNSCC cell cycle changes, we examined the cell cycle regulators possibly targeted by miR-17-5p. Using the bioinformatics tool, we identified CCNG2 mRNA as one of the putative targets of miR-17-5p due to its involvement in the inhibition of tumor proliferation and cell cycle $[7,19]$. We found that miR-17-5p expression level was higher than that of CCNG2 in 497 HNSCC samples, and there was a significant negative correlation between miR-17-5p and CCNG2 $(r=-0.105, p=0.0191$; Fig. 3A). In AMC-HN8 and FaDu cells, the inhibition of miR-17-5p almost doubled CCNG2 mRNA levels compared with cells transfected with the negative control, and overexpression of miR-17-5p in Tu686 and Detriot562 led to a decrease in CCNG2 mRNA of approximately $60-75 \%$ (Fig. 3B). Similarly, the inhibition of miR-17-5p increased the CCNG2 protein level (only in $\mathrm{FaDu}$ cells), which was reversed following the overexpression of miR-17-5p (only in Tu686 cells) (Fig. 3C). 


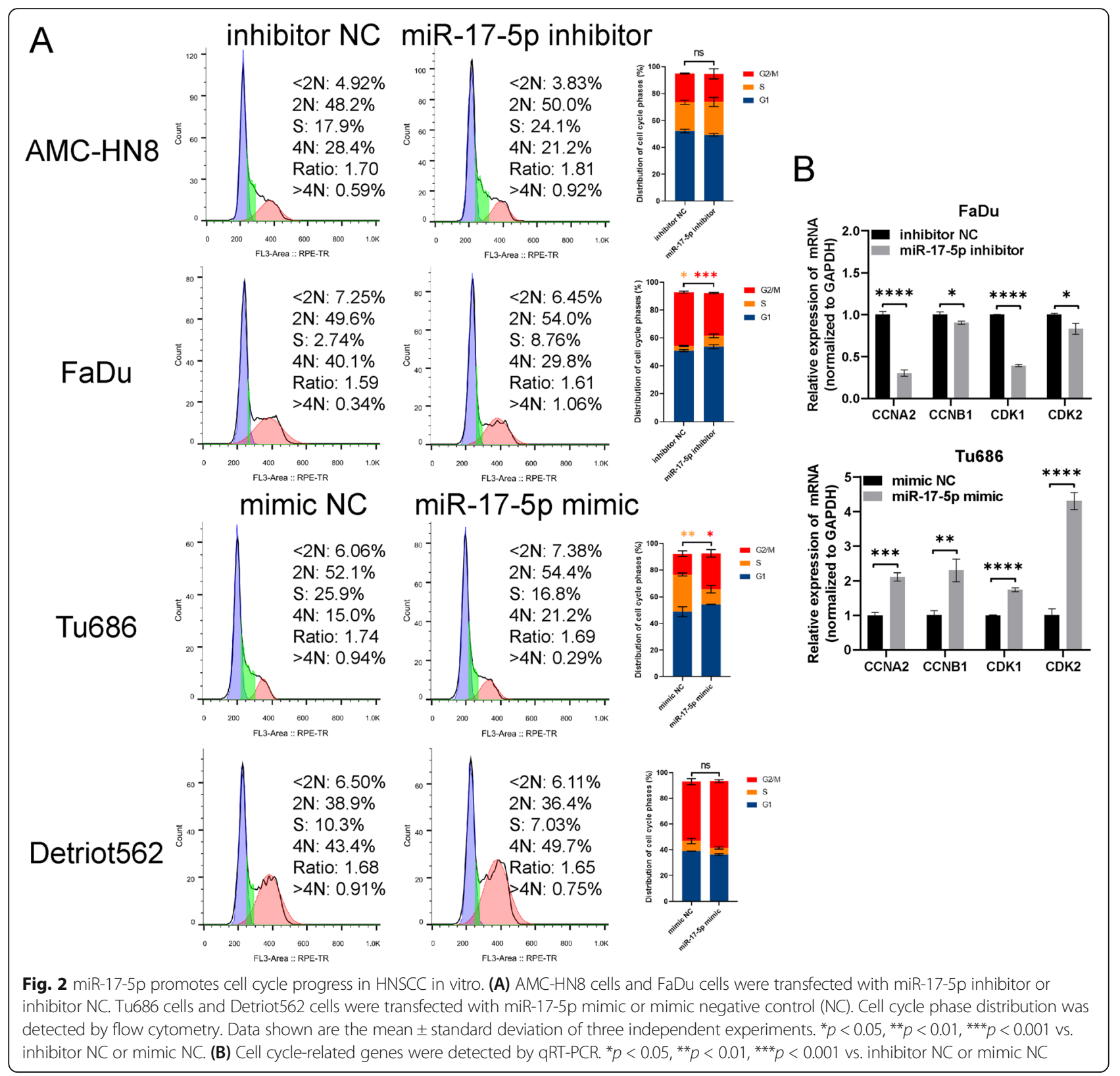

To determine whether CCNG2 is a direct target gene of miR-17-5p, we performed a dual-luciferase reporter assay. The binding sites for miR-17-5p in the 3'UTR of CCNG2 are illustrated in Fig. 3D. CCNG2-3'UTR wt1/2 or CCNG2-3'UTR-mu1/2 was co-transfected with miR17-5p mimic or mimic NC into $293 \mathrm{~T}$ cells. Fluorescence intensity was decreased by $25-29 \%$ in cells co-transfected with miR-17-5p mimic and CCNG2-3'UTR-wt1/2. However, neither the miR-17-5p mimic nor mimic NC affected the fluorescence intensity of cells transfected with CCNG2-3'UTR-mu1/2 (Fig. 3E). These findings indicate that miR-17-5p directly targets CCNG2, which may drive the alteration of the HNSCC cell cycle.

\section{CCNG2 inhibits cell cycle progress in HNSCC in vitro}

To determine the function of CCNG2 in the cell cycle, we initially detected the endogenous expression level of CCNG2 in HNSCC cells. We found that CCNG2 was down-regulated in Tu686 and FaDu cell lines compared with HuLa-PC cells (Fig. 4A). The intracellular CCNG2 mRNA and protein level was greatly increased by transfecting the CCNG2 specific plasmid (Fig. 4B, C). We also observed that overexpression of CCNG2 caused an increase in Tu686 cells at the G1 phase (from 60.9 to $68 \%$ ) and a decrease in $\mathrm{FaDu}$ cells at G2/M phase (from 28.8 to $20.2 \%$; Fig. 4D), which was consistent with the results of miR-17-5p inhibition (Fig. 2A). CCND1 and CDK6, 


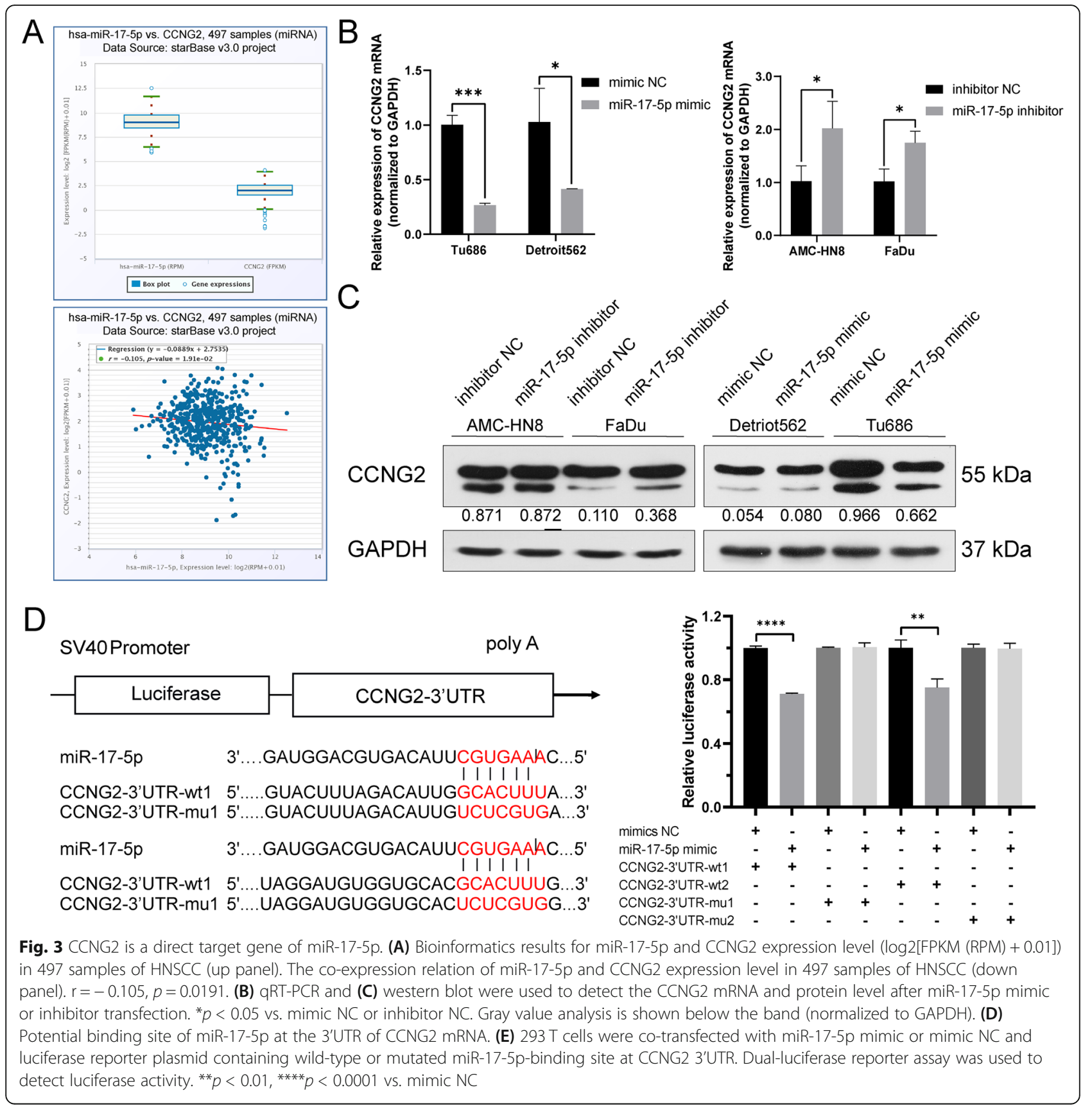

which induce cell cycle progression in CCNG2overpressed Tu686 cells, were reduced. CCNB1 was reduced in FaDu cells overexpressing CCNG2 (Fig. 4E). Taken together, these data suggest that CCNG2 inhibits cell cycle progress in HNSCC in vitro.

\section{Discussion}

Cell cycle alteration is one of the factors that causes malignant cell behaviors observed in cancer, such as proliferation, invasion and chemo-resistance [4]. miR-
$17-5 p$ is a member of the miR-17-92 cluster, which plays an important role in the tumorigenesis of different cancers. Kim et al. found that miR-17-5p regulates epithelial-mesenchymal transition (EMT) by targeting vimentin in colorectal cancer (CRC) [20]. In gastric cancer, miR-17-5p has been shown to promote cellular proliferation and invasiveness by targeting RUNX3 [21]. However, the cell cycle regulation mechanism mediated by miR-17-5p is still unclear, especially in HSNCC. 


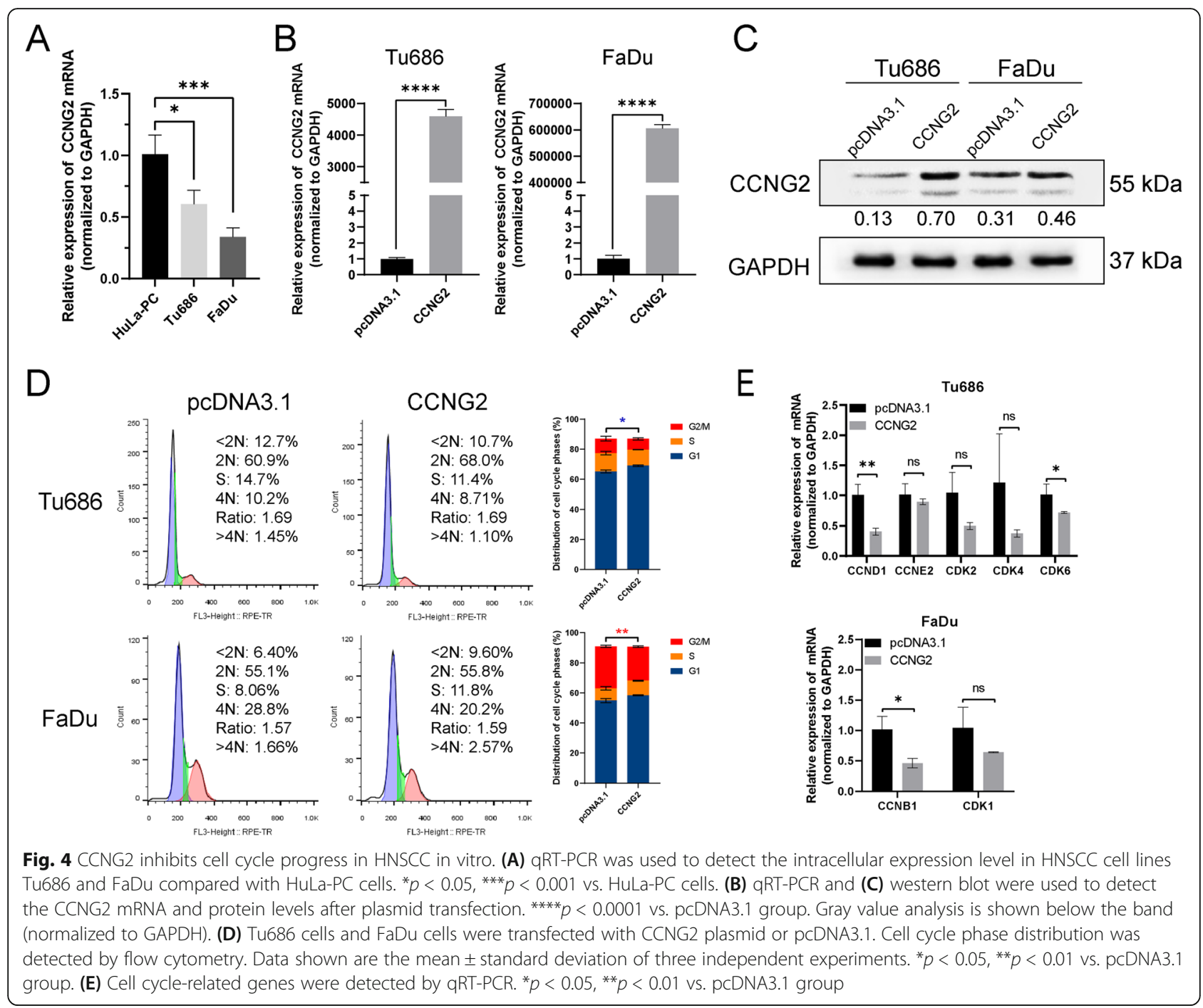

The expression of miR-17-5p was reportedly upregulated in the plasma and tissues of patients with gastric cancer [21]. Wang et al. reported that miR-17-5p is upregulated in laryngeal squamous cell carcinoma (LSCC) tissues and cell lines. More importantly, they found that compared with patients with lower miR-17-5p expression level, patients with higher miR-17-5p expression levels in LSCC tissues have a poorer survival rate [5]. Consistently, in the present study, we observed an increased level of miR-17-5p in HNSCC tissues and cell lines. Surprisingly, HNSCC patients with higher levels of miR-17-5p had a higher likelihood of recurrence compared with patients who had a lower level of miR-17-5p, suggesting that miR-17-5p is related to recurrence in HNSCC patients. There are also reports on the results with some conflicting conclusions. Kim et al. found that miRNA-17-5p expression was lower in primary CRC tissues with metastasis than in primary CRC tissues without metastasis [20]. Fan et al. identified miR-17-5p as a metastatic suppressor of basal-like breast cancer [22] We speculate that the differences between the promotion and inhibition of miR-17-5p may attributed to the organ-specific function of miRNA [20] and different target genes from those regulated by miR-17-5p as described by Cloonan et al. [6].

In the present study, we found that miR-17-5p promoted cell cycle progression of HNSCC cells mainly by increasing the proportion of cells in G2/M phase and reducing the proportion of cells in S phase. More importantly, we verified miR-17-5p negatively regulated CCNG2 mRNA and protein expression by directly targeting its 3'UTR, indicating that miR-17-5p might act as a tumor promoter in HNSCC. However, other teams have reported different mechanisms by which miR-17$5 \mathrm{p}$ promotes cell cycle progression. Cloonan et al. found miR-17-5p acts specifically at the G1/S-phase cell cycle boundary by targeting more than 20 genes involved in the transition between these phases [6]. Li et al. found 
that miR-17-5p promoted cell proliferation by promoting cell cycle G1/S transition and inhibiting ovarian cancer cell apoptosis, while inhibition of miR-17-5p resulted in the opposite [18]. Zhu et al. found that inhibition of miR-17-5p in pancreatic cancer cells resulted in a higher proportion of cells within the G1 phase and less in the S phase, leading to impaired proliferation of the cancer cells [9]. The results of these studies demonstrate that miR-17-5p mainly acts on the G1/S boundary in promoting cell cycle progression. Although the mechanism of action in our study is different from that reported by other teams, we all elucidate the role of miR-17-5p in promoting cell cycle progression. This difference may be largely due to the role of miR-17-5p target gene in cell cycle regulation.

Although most of the evidence in the literature supports a role for CCNG2 in limiting G1/S phase transition $[23,24]$, there are indications that CCNG2 could participate in G2/M regulation $[23,25,26]$. We previously proved that CCNG2 siRNA application in LSCC cell lines contributes to the increased G2/M phase proportion [16]. This is consistent with our findings that the overexpression of CCNG2 in FaDu cells led to a decrease in the G2/M phase proportion.

There are several limitations to our study. There are many targets of miR-17-5p other than CCNG2. It is possible that multiple mechanisms are at play. Additional in vivo research should be conducted if miR-17-5p and CCNG2 are to be considered therapeutic targets in HNSCC treatment. Although the direct regulatory relationship between the miR-17-5p and CCNG2 was confirmed by the dual-luciferase reporter assay, cell rescue experiments and in vivo animal experiments are needed for further verification.

\section{Conclusion}

Clearly, our results demonstrate that miR-17-5p regulates the cell cycle of HNSCC cells by directly targeting CCNG2 and is related to recurrence in HNSCC patients. Further exploration of these molecules and a better understanding of miR-17-5p will help develop more effective therapies against HNSCC.

\section{Abbreviations}

HNSCC: Head and neck squamous cell carcinoma; Cyclin G2: CCNG2; RTqPCR: Real-time quantitative polymerasechain reaction; miRNAs: microRNAs; UTR: Untranslated region; LSCC: Laryngeal squamous cell carcinoma; EMT: Epithelial-mesenchymal transition; CRC: Colorectal cancer

\section{Acknowledgements}

We thank all the patients who participated in this study for providing the samples and clinical data.

\section{Authors' contributions}

$\mathrm{QH}$ and $\mathrm{LZ}$ designed the experiments and analyzed the data. QH, YJS and $\mathrm{CYH}$ performed the experiments. $\mathrm{QH}$ wrote the manuscript and $\mathrm{LZ}$ revised it. YG, YFZ and JYL contributed to the enrolment of patients, collection and processing of clinical samples, and collection and analysis of clinical data. All authors have read and approved the final manuscript.

\section{Funding}

The present study was supported by grants from the National Natural Science Foundation of China [No. 81972529] and the Science and

Technology Commission of Shanghai Municipality [No. 19411961300].

\section{Availability of data and materials}

All the source data supporting the findings of this study are available from the corresponding author upon reasonable request.

\section{Declarations}

\section{Ethics approval and consent to participate}

All participants provided written informed consent. The protocols were authorized by the The experimental protocol was established, according to the ethical guidelines of the Helsinki Declaration and was approved by the Clinical Research Ethics Committee of the Eye \& ENT Hospital of Fudan University (NO.KJ2008-01). Written informed consent was obtained from individual or guardian participants.

\section{Consent for publication}

Not applicable.

\section{Competing interests}

The authors declare that they have no known competing financial interests or personal relationships that could have influenced the work reported in this paper.

\section{Author details}

'Department of Otorhinolaryngology, Eye \& ENT Hospital, Fudan University, Shanghai 200031, China. ${ }^{2}$ Department of Pediatric, Xinhua Hospital, Shanghai Jiaotong University School of Medicine, Shanghai 200092, China.

Received: 8 July 2021 Accepted: 27 September 2021

Published online: 02 October 2021

\section{References}

1. Chow LQM. Head and neck Cancer. N Engl J Med. 2020;382(1):60-72. https://doi.org/10.1056/NEJMra1715715

2. Siegel RL, Miller KD, Jemal A. Cancer statistics, 2020. CA Cancer J Clin. 2020; 70(1):7-30. https://doi.org/10.3322/caac.21590.

3. Zhao H, Yi B, Liang Z, Phillips C'N, Lin HY, Riker Al, et al. Cyclin G2, a novel target of sulindac to inhibit cell cycle progression in colorectal cancer. Genes Dis. 2020;\$2352304220301379(3):320-30. https://doi.org/10.1016/j. gendis.2020.11.006.

4. Hanahan D, Weinberg RA. Hallmarks of Cancer: the next generation. Cell. 2011;144(5):646-74. https://doi.org/10.1016/j.cell.2011.02.013.

5. $\quad$ Wang J-X, Jia X-J, Liu Y, Dong JH, Ren XM, Xu O, et al. Silencing of miR-17$5 p$ suppresses cell proliferation and promotes cell apoptosis by directly targeting PIK3R1 in laryngeal squamous cell carcinoma. Cancer Cell Int. 2020;20(1):14. https://doi.org/10.1186/s12935-020-1096-3.

6. Cloonan N, Brown MK, Steptoe AL, Wani S, Chan W, Forrest ARR, et al. The miR-17-5p microRNA is a key regulator of the G1/S phase cell cycle transition. Genome Biol. 2008;9(8):R127. https://doi.org/10.1186/ gb-2008-9-8-r127.

7. Xiao X, Zhou L, Cao P, et al. MicroRNA-93 regulates cyclin G2 expression and plays an oncogenic role in laryngeal squamous cell carcinoma. Int J Oncol. 2015;46(1):161-74. https://doi.org/10.3892/ijo.2014.2704.

8. He L, Thomson JM, Hemann MT, Hernando-Monge E, Mu D, Goodson S, et al. A microRNA polycistron as a potential human oncogene. Nature. 2005; 435(7043):828-33. https://doi.org/10.1038/nature03552.

9. Zhu Y, Gu J, Li Y, Peng C, Shi M, Wang X, et al. MiR-17-5p enhances pancreatic cancer proliferation by altering cell cycle profiles via disruption of RBL2/E2F4-repressing complexes. Cancer Lett. 2018;412:59-68. https://doi. org/10.1016/j.canlet.2017.09.044.

10. Cao P, Zhou L, Zhang J, Zheng F, Wang H, Ma D, et al. Comprehensive expression profiling of microRNAs in laryngeal squamous cell carcinoma. Head Neck. 2013;35(5):720-8. https://doi.org/10.1002/hed.23011. 
11. Ohno S, Ikeda J, Naito Y, Okuzaki D, Sasakura T, Fukushima K, et al. Comprehensive phenotypic analysis of knockout mice deficient in cyclin G1 and cyclin G2. Sci Rep. 2016;6(1):39091. https://doi.org/10.1038/srep39091.

12. Horne MC, Goolsby GL, Donaldson KL, Tran D, Neubauer M, Wahl AF. Cyclin G1 and Cyclin G2 comprise a new family of Cyclins with contrasting tissuespecific and cell cycle-regulated expression. J Biol Chem. 1996;271(11):605061. https://doi.org/10.1074/jbc.271.11.6050.

13. Lin S-S, Peng C-Y, Liao Y-W, et al. miR-1246 Targets CCNG2 to Enhance Cancer Stemness and Chemoresistance in Oral Carcinomas. Cancers [Internet]. 2018;10 [cited 2018 Sep 4]. Available from: https://www.ncbi.nlm. nih.gov/pmc/articles/PMC6115994/.

14. Kim SY, Chu KC, Lee HR, Lee KS, Carey TE. Establishment and characterization of nine new head and neck cancer cell lines. Acta Otolaryngol (Stockh). 1997;117(5):775-84. https://doi.org/10.3109/000164 89709113477.

15. Lee S-H, Samuels T, Bock JM, Blumin JH, Johnston N. Establishment of an immortalized laryngeal posterior commissure cell line as a tool for reflux research. Laryngoscope. 2015;125(2):E73-7. https://doi.org/10.1002/ lary.24952.

16. Huang Q, Hsueh C, Guo Y, et al. Lack of miR-1246 in small extracellular vesicle blunts tumorigenesis of laryngeal carcinoma cells by regulating Cyclin G2. IUBMB Life. 2020;72(7):1491-503. https://doi.org/10.1002/iub.2274.

17. Huang Q, Hsueh C-Y, Shen Y-J, Guo Y, Huang JM, Zhang YF, et al. Small extracellular vesicle-packaged TGF $\beta 1$ promotes the reprogramming of normal fibroblasts into cancer-associated fibroblasts by regulating fibronectin in head and neck squamous cell carcinoma. Cancer Lett. 2021; 517:1-13. https://doi.org/10.1016/j.canlet.2021.05.017.

18. Li L, He L, Zhao J-L, Xiao J, Liu M, Li X, et al. MiR-17-5p up-regulates YES1 to modulate the cell cycle progression and apoptosis in ovarian Cancer cell lines. J Cell Biochem. 2015;116(6):1050-9. https://doi.org/10.1002/jcb.25060.

19. Zimmermann M, Arachchige-Don APS, Donaldson MS, Patriarchi T, Horne MC. Cyclin G2 promotes cell cycle arrest in breast cancer cells responding to fulvestrant and metformin and correlates with patient survival. Cell Cycle. 2016;15(23):3278-95. https://doi.org/10.1080/15384101.2016.1243189.

20. Kim TW, Lee YS, Yun NH, Shin CH, Hong HK, Kim HH, et al. MicroRNA-17-5p regulates EMT by targeting vimentin in colorectal cancer. Br J Cancer. 2020; 123(7):1123-30. https://doi.org/10.1038/s41416-020-0940-5.

21. Song J, Liu Y, Wang T, Li B, Zhang S. MiR-17-5p promotes cellular proliferation and invasiveness by targeting RUNX3 in gastric cancer. Biomed Pharmacother. 2020;128:110246. https://doi.org/10.1016/j. biopha.2020.110246.

22. Fan M, Sethuraman A, Brown M, Sun W, Pfeffer LM. Systematic analysis of metastasis-associated genes identifies miR-17-5p as a metastatic suppressor of basal-like breast cancer. Breast Cancer Res Treat. 2014;146(3):487-502. https://doi.org/10.1007/s10549-014-3040-5.

23. Zimmermann M, Arachchige-Don AS, Donaldson MS, Dallapiazza RF, Cowan CE, Horne MC. Elevated Cyclin G2 expression intersects with DNA damage checkpoint signaling and is required for a potent G2/M checkpoint arrest response to doxorubicin. J Biol Chem. 2012;287(27):22838-53. https://doi. org/10.1074/jbc.M112.376855

24. Bennin DA, Don ASA, Brake T, McKenzie JL, Rosenbaum H, Ortiz L, et al. Cyclin $\mathrm{G} 2$ associates with protein phosphatase $2 \mathrm{~A}$ catalytic and regulatory $\mathrm{B}^{\prime}$ subunits in active complexes and induces nuclear aberrations and a G1/S phase cell cycle arrest. J Biol Chem. 2002;277(30):27449-67. https://doi.org/1 0.1074/jbc.M111693200.

25. Adorno M, Cordenonsi M, Montagner M, Dupont S, Wong C, Hann B, et al. A mutant-p53/Smad complex opposes p63 to empower TGF $\beta$-induced metastasis. Cell. 2009;137(1):87-98. https://doi.org/10.1016/j.cell.2009.01.039.

26. Shimizu A, Nishida J, Ueoka Y, Kato K, Hachiya T, Kuriaki Y, et al. CyclinG contributes to G2/M arrest of cells in response to DNA damage. Biochem Biophys Res Commun. 1998;242(3):529-33. https://doi.org/10.1006/bbrc.1 997.8004.

\section{Publisher's Note}

Springer Nature remains neutral with regard to jurisdictional claims in published maps and institutional affiliations.

\section{Ready to submit your research? Choose BMC and benefit from}

- fast, convenient online submission

- thorough peer review by experienced researchers in your field

- rapid publication on acceptance

- support for research data, including large and complex data types

- gold Open Access which fosters wider collaboration and increased citations

- maximum visibility for your research: over $100 \mathrm{M}$ website views per year

At BMC, research is always in progress.

Learn more biomedcentral.com/submissions 